\title{
SUSTENTABILIDADE E ENTROPIA NA GERAÇÃO TEXTUAL VARIACIONAL: POEMADS - SOB O SIGNO DA DEVORAÇÃO*
}

Rui Torres ${ }^{*}$

RESUMO: Descrição e contextualização teórica de um conjunto de poemas digitais realizados com o apoio do motor textual Poemário, seguindo procedimentos combinatórios e generativos. Este trabalho de literatura electrónica foi programado a partir da conjugação de vários slogans publicitários, constituindo dessa forma uma plagiotropia e uma devoração da publicidade actual. O léxico que alimenta estes processos foi tratado e seleccionado a partir de aproximadamente 10.000 anúncios publicitários e propagandísticos em língua portuguesa.

PALAVRAS-CHAVE: Ciberliteratura. Combinatória e generatividade textual. Plagiotropia e releitura. Teoria da Informação.

\section{Détournement e plagiotropia - Releitura como produção e ecologia}

PoemAds é um conjunto de poemas combinatórios e generativos que promovem a deformação e transformação de campanhas publicitárias e seus slogans.

No seu texto "Mode d'emploi du détournement", de 1956, Guy Debord \& Gil J Wolman sugeriam que

It is in the advertising industry, more than in the domain of decaying aesthetic production, that one can find the best examples [of détournement]. (...) The distortions introduced in the detourned elements must be as simplified as possible, since the main impact of a détournement is directly related to the conscious or semiconscious recollection of the original contexts of the elements. (...) In itself, the theory of détournement scarcely interests us. But we find it linked to almost all the constructive aspects of the presituationist period of transition. Thus its enrichment, through practice, seems necessary. (DEBORD e WOLMAN, 2006, on-line).

Artigo produzido no âmbito do Projecto "PO.EX'70-80 - Arquivo Digital da Literatura Experimental Portuguesa", financiado pela Fundação para a Ciência e a Tecnologia com fundos do MCTES e do FEDER/UE (Refá: PTDC/CLE-LLI/098270/2008).

"Universidade Fernando Pessoa. Imeio: rtorres@ufp.edu.pt.



Texto Digital, Florianópolis, v. 8, n. 2, p. 361-375, jul./dez. 2012. ISSNe: 1807-9288 
A este apelo à devoração devemos associar o famoso texto de Fernando Namora, "Marketing", em que o poeta e escritor avisava: "Atenção ao marketing. (...) / Ninguém contraria o marketing por muito tempo. / Ninguém contraria os fabricantes de bem fazer / o bom cidadão. / E tudo graças ao marketing. " (NAMORA, 1970, p. 16).

Banksy, no seu livro Cut It Out, inspirado por artigo de Sean Tejaratchi publicado na revista Crap Hound (1999), é mais directo: "Fuck That. Any advert you see in a public space that gives you no choice whether you see it or not is yours to take, re-arrange and re-use. You can do whatever you like with it. Asking for permission is like asking to keep a rock someone just threw at your head." (BANKSY, 2004).

No seu estudo acerca da paródia, Linda Hutcheon reconhece que a intertextualidade e a auto-representação - a narrativa que se apresenta como artifício, isto é, a capacidade de um texto se referir a si mesmo -, dominam, a partir de Ezra Pound e T. S. Eliot, a atenção crítica (HUTCHEON, 1989, p. 12). Para a autora, este crescente interesse permite o surgimento de "uma estética do processo, da actividade dinâmica da percepção, interpretação e produção" das obras de arte (HUTCHEON, 1989, p. 12). Hutcheon define entretanto a paródia como "repetição com distância crítica, que marca a diferença em vez da semelhança" (HUTCHEON, 1989, p. 17), ao mesmo tempo que a define como "relação estrutural e funcional de revisão crítica" (HUTCHEON, 1989, p. 27).

Também Maria dos Prazeres Gomes, em Outrora Agora, procura "cartografar" as relações dialógicas na poesia portuguesa de invenção, aquilo a que, tomando emprestado o termo a Haroldo de Campos, chamou de "movimento plagiotrópico das formas culturalmente fixadas" (GOMES, 1993, p. 19). Gomes utiliza, entre outros exemplos, um texto de Herberto Helder d'A Máquina de Emaranhar Paisagens, que se inscreve nos textos experimentais que encenam a transformação e a devoração da tradição. Ao incluir este poema num vasto 
conjunto de textos marcados por uma "atitude crítico-lúdico-transgressora" (GOMES, 1993, p. 22), Gomes acaba por definir a plagiotropia dentro de um espaço conceitual (GOMES, 1993, p. 20) que engloba uma série de conceitos teóricos, tais como os de metalinguagem, intertextualidade, dialogismo e paródia. Embora reconheça todos estes conceitos, a atitude crítico-lúdicotransgressora da poesia portuguesa envolve, segundo a autora, uma acrescida "operação tradutora no sentido de releitura crítica da tradição" (GOMES, 1993, p. 20). Como resultado, a autora inaugura a plagiotropia como um "movimento inalienável da literatura” (GOMES, 1993, p. 20).

\section{Combinatória e generatividade aleatória - Escrileitura como reconstrução e sinergia}

Em Electronicolírica (1964), Herberto Helder faz uso do processo combinatório pela primeira vez. No posfácio da primeira edição desse livro, referindo-se a uma experiência com uma calculadora electrónica que Nanni Balestrini levou a cabo em Milão em 1961, processando, segundo certas regras combinatórias previamente estabelecidas, textos antigos e modernos, de que resultaram 3002 combinações, Helder explica que a mesma atitude é levada a cabo no seu livro, através de um processo de transferência, sem porém se "cingir a qualquer regra" (HELDER, 1964, p. 49). Daí resultou, de acordo com o poeta, uma semelhança com "certos textos mágicos primitivos, a certa poesia popular, a certo lirismo medieval" (HELDER, 1964, p. 50), criando assim uma peculiar "fórmula ritual mágica, de que o refrão popular é um vestígio e de que é vestígio também o paralelismo medieval, exemplificável com as cantigas dos cancioneiros" (HELDER, 1964, p. 50). Helder acaba por concluir que "[0] princípio combinatório é, na verdade, a base linguística da criação poética" (HELDER, 1964, p. 50).

Pedro Barbosa, pioneiro da ciberliteratura, tem recentemente estudado aquilo que considera uma "literatura quântica", isto é, "todo o tipo de textos programados em computador segundo estruturas generativas dinâmicas, automáticas, variacionais, reticulares ou interactivas, onde a multiplicidade dos 
sentidos e a indeterminação das formas os aproxima das propriedades dos objectos quânticos" (BARBOSA, 2006, p. 16).

Proponente do termo "texto virtual" para descrever o seu próprio trabalho criativo realizado com o gerador textual Sintext, Barbosa define do seguinte modo esta nova forma de textualidade: "os textos são concebidos primeiro em estado potencial (é o que chamámos de texto-matriz) e só depois são vertidos, mediante um procedimento combinatório ou aleatório, num campo variacional infinito - só nesse campo variacional os textos passam a existir realmente como textos materiais em estado legível." (BARBOSA, 2006, p. 19).

As implicações do texto virtual ou quântico, segundo Barbosa, vão além da técnica:

O mais perturbante, quando se lida com 0 acaso na linguagem segundo a lei dos grandes números, é observar como do caos dos significados tratados pela máquina parece emergir uma ordem no plano do sentido. É como se o acaso na linguagem desse também sentido aos textos emergentes da desordem e abrisse ao leitor portas inéditas de compreensão do real... Do nosso ponto de vista, há uma tal homologia que liga esta textualidade à ordem profunda do universo! (BARBOSA, 2006, p. 28).

\section{Informação e complexidade - Poesia como descobrimento e desocultação}

Do ponto de vista crítico, ligar o détournement e a paródia, a apropriação e a plagiotropia, a uma nova noção de texto generativo e combinatório, obriga-nos a recorrer à teoria da informação, bem como sua aplicação nos estudos de estética por Abraham Moles e Max Bense, entre outros. Para este último, a realidade estética surge como uma realidade autónoma face à realidade física: "[a] realidade estética é constituída por processos que são o contrário dos processos físicos." (BENSE, 1975, p. 231). Para Bense, a evolução do processo estético conduz, inevitavelmente, à informação, enquanto que a evolução do processo físico leva à entropia. Bense diferencia, assim, um processo lógico, "o provável, o costumeiro, o não-surpreendente," e um 
processo estético, a que está associado "o improvável, o não costumeiro, o surpreendente" (BENSE, 1975, p. 172).

A própria concepção poética contemporânea é entendida por E. M. de Melo e Castro, igualmente pioneiro na utilização de meios tecnológicos para produção literária, em termos de informação. No livro que sintetiza e introduz a poesia concreta e experimental em Portugal, A proposição 2.01, Melo e Castro dá grande importância à teoria da informação, concluindo que "[o] trabalho criador do artista experimental é precisamente produzir estruturas de grande entropia, pois quanto maior for a entropia dessas estruturas maior e mais vasta será a informação possível; maior será portanto a pluralidade significativa da obra de arte." (MELO E CASTRO, 1965, p. 100)

$\mathrm{Na}$ versão de Moles, a informação surge também associada a uma noção de valor. Para ser mais valiosa, deve trazer modificações no comportamento do receptor, uma vez que o que é conhecido não modifica nada, antes é internalizado pelo receptor (MOLES, 1966, p. 19). O valor está, assim, associado ao inesperado, ao desconhecido e ao que é original.

Moles estabelece, a partir da teoria da informação, duas categorias: a informação semântica e a informação estética. Esta distinção permite diferenciar dois modos de informação presentes em toda e qualquer mensagem. No caso da poesia e de outras mensagens de carácter artístico, a informação estética é mais elevada do que a informação semântica, ocupando, por isso, um lugar central.

Moles entende estes dois tipos de informação como pontos de vista distintos. $O$ ponto de vista semântico é "logical, structured, expressible, translatable viewpoint [that] prepares actions" (MOLES, 1966, p. 128), enquanto que 0 ponto de vista estético é intraduzível, na medida em que não existe autonomamente como linguagem. A intenção do último é alterar e modificar estados de consciência, e, para isso, refere-se a um repertório individualizado e particular. 
Por outro lado, a um aumento ao nível da complexidade e originalidade corresponde igualmente a sua capacidade reflexiva. Avançando contra as expectativas do leitor, a poesia, como explicou Viktor Shklovsky, promove a ostraneniye, um efeito de estranhamento. Assim, na mesma medida em que o uso normal do código automatiza as reacções, a arte as desautomatiza e liberta.

Estas duas formas distintas de percepção, automatizada e estética, levam Shklovsky a designar a primeira como um hábito, uma espécie de alienação ou, nas suas palavras, um "método algébrico de raciocínio", uma espécie de economia de inteligência. Para o autor, o alcance desta banalização da vida é enorme. Ela percorre toda a experiência humana: "Habitualization devours works, clothes, furniture, one's wife, and the fear of war" (SHKLOVSKY, 1989, p. 58).

A esta percepção automatizada, porém, Shklovsky contrapõe a percepção estética, que é vinculada pela arte e que permite ver a beleza natural dos objectos e das coisas. A arte e a poesia contemporânea existiriam para contrapôr a tendência automatizadora: "it exists to make one feel things, to make the stone stony. The purpose of art is to impart the sensation of things as they are perceived and not as they are known" (SHKLOVSKY, 1989, p. 58).

Para desautomatizar a linguagem, a arte deve começar por dificultar a percepção, já que "the process of perception is an aesthetic end in itself and must be prolonged" (SHKLOVSKY, 1989, p. 58).

\section{Poemário - Détournement e plagiotropia; combinatória e generatividade aleatória; informação e complexidade}

O software Poemário ${ }^{1}$ é inspirado nas experiências de Pedro Barbosa e Nanni

TORRES, R. \& FERREIRA, N. F. (2008). Poemário - Blog de poesia combinatória /
Comunidade de leitores de poesia automática. <http://telepoesis.net/poemario>; TORRES, R. \& 
Balestrini, entre outros. Trata-se de uma aplicação escrita em Actionscript 3 que permite ao seu utilizador construir textos (poemas, narrativas, cartas, etc.) seguindo procedimentos combinatórios. Até certo ponto, constitui uma actualização, ou recriação, do Sintext, de Pedro Barbosa, Abílio Cavalheiro e José M. Torres. As suas bases de configuração poética estão presentes nos trabalhos experimentais de E. M. de Melo e Castro e Herberto Helder.

PoemAds usa este software, pelo que explicarei aqui o seu modo de funcionamento.



Fig. 1 - Software Poemário, de Rui Torres e Nuno F. Ferreira

\section{Poemário - Definição do Poema}

$\mathrm{Na}$ área relativa a "1. Definição do Poema", o autor deve inserir o texto que

FERREIRA, N. F. (2008). Poemário - Editor de poesia combinatória. Software. <http://telepoesis.net/galeria-poemas/peditor.php>. Créditos: Rui Torres: conceito; Nuno F. Ferreira: programação. 
pretende programar. Cada quebra de linha deve ter correspondência com uma quebra de linha no texto a inserir. Sigamos o exemplo de um verso de Herberto Helder: "são palavras pronunciadas com medo de pousar."

Imediatamente a seguir a cada palavra que pretendemos submeter a uma regra combinatória, deve-se colocar \$categoria (sem espaços). No caso do verso em exemplo, utilizaremos as seguintes categorias: \$subs_f_p, \$adjs_f_p, \$subs_m_s, \$verbos_inf, em que subs = substantivos, adjs = adjectivos; $\_f=$ feminino $e \_m=$ masculino; $\_s=$ singular $e \_p-$ plural.

Assim: "são palavras\$subs_f_p pronunciadas\$adjs_f_p com medo\$subs_m_s de pousar\$verbos_inf".

A criação das listas pode ser feita a partir de listas exclusivamente criadas pelo utilizador, mas pode também partir de algumas categorias já existentes. Para facilitar o trabalho do utilizador, existem já algumas listas de vocabulário. Eis as listas de palavras disponíveis, entre outras: \$verbos_inf = verbos infinitivo; \$verbos_ger $=$ verbos gerúndio; $\$$ verbos_pr_p $=$ verbos presente $3^{\underline{a}}$ pessoa plural; $\$$ verbos_pr_s $=$ verbos presente $3^{\mathrm{a}}$ pessoa singular; $\$$ subs_m_s $=$ substantivos masculino singular; $\$$ subs_f_s $=$ substantivos feminino singular; \$subs_m_p = substantivos masculino plural; \$subs_f_p = substantivos feminino singular; \$adjs_m_s = adjectivos masculino singular; $\$$ adjs_f_s $=$ adjectivos feminino singular; $\$$ adjs_ $m \_p=$ adjectivos masculino plural; $\$$ adjs_f_p = adjectivos feminino plural.

\section{Poemário - Criação de Categorias e Listas}

O utilizador pode escrever o seu poema e pretender criar listas de palavras (categorias) ou usar categorias e listas já criadas para esse efeito. Para criar novas categorias referidas no poema, deve em primeiro lugar criar a categoria (com o nome que desejar, desde que ele corresponda ao referido na etapa 1. Depois de escrever o nome da categoria na caixa de texto disponível para o efeito, deve clicar no botão "Criar categoria". Depois de clicar nesse botão, 
deve abrir a lista de categorias disponível e encontrar a categoria que criou, escolhendo-a. Depois de estar dentro da nova categoria criada, pode inserir as palavras, separadas por linha, na área disponível do lado esquerdo.

O utilizador pode também escolher as listas utilizadas no seu poema, apagando, alterando ou inserindo as palavras que desejar. Após inserir o cursor na área em que aparecem as palavras, poderá, com a ajuda do rato, seleccionar as palavras que pretende retirar, utilizando posteriormente a tecla de apagar do seu computador. Para seleccionar todas as palavras, utilizando desse modo as categorias mas não as listas de palavras, pode utilizar o atalho de teclas $\mathrm{Ctrl}+\mathrm{A}$.

Quer utilize as categorias e listas existentes ou não, tem sempre que, após edição das categorias e listas, validar o processo, clicando no botão "Guardar Categoria" para garantir que as alterações às listas são gravadas (temporariamente) na base de dados.

\section{Poemário - Configuração / Opções}

Depois de programado o poema (passo 1) e de criadas as categorias e listas de palavras (passo 2), o utilizador tem a opção de configurar algumas opções de funcionamento do poema, que aqui se resumem:

A Animação automática: Se esta opção for seleccionada, o poema anima as palavras programadas de um modo automático e aleatório (sem interacção do leitor). Se pretender interacção do leitor (isto é, que o leitor tenha que clicar nas palavras para processar a combinatória respectiva), deixe esta opção em branco.

A Com edição de lista: Se esta opção for seleccionada, o leitor do poema terá acesso às listas de palavras programadas, podendo invocá-las e alterá-las a seu gosto, clicando para isso em cima da respectiva palavra com o botão Control (Ctrl) pressionado ao mesmo tempo. Se pretender que o leitor não possa ter acesso às listas, deixe esta opção em branco. 
A Edita c/ ctrl + click: Mesmo que descrição do ponto anterior, mas apenas aplicável caso tenha seleccionado a opção "animação automática".

A Com som: Permite utilizar som combinatório no seu poema, além do texto. Se esta opção for seleccionada, o poema terá som (terá que configurar também as listas de som, explicadas em baixo). Se pretender que o poema não tenha som, deixe esta opção em branco.

A Lista por palavra: Se reutilizar categorias no seu poema-programa (uma mesma lista de substantivos para duas ou mais palavras diferentes), sempre que o utilizador alterar as listas, ele vai alterar também essa lista no que diz respeito a todas as restantes palavras atribuídas a essa categoria. Por isso, se a opção "lista por palavra" estiver seleccionada aqui, permite que o Poemário, no momento da leitura, atribua a cada palavra uma lista igual, mas que pode ser alterada em alterar as restantes.

Se decidir usar som combinatório no seu poema (opção "com som" anteriormente referida), tem ainda as seguintes opções:

A Intervalo sons: Pode utilizar o slider para aumentar ou diminuir o tempo de intervalo entre a leitura (sempre aleatória) dos sons disponíveis na base de dados. Por defeito, o tempo de intervalo é de 1 segundo (tempo medido entre final de som e início do próximo).

A $A$ e $B$ : Antes de "reusar" sons existentes ou de "fazer upload" dos seus próprios sons (ver ponto seguinte), tem que escolher qual das listas está a editar. O programa de som está feito de forma a que, em duas determinadas listas de sons, sejam invocados ficheiros, de um modo alternado e aleatório.

A Reusar: Pode utilizar sons disponíveis na base de dados do Poemário, usados em poemas já programados e disponíveis em rede. Pode seleccionar os sons existentes (do lado esquerdo), "Ouvir", "Adicionar" à sua própria lista (do lado direito). Pode também, depois de ter adicionado os sons, "Retirar" esses sons. Depois de ter feito a sua selecção, clique no botão "Fechar". 
A Upload: Pode, se preferir, fazer upload de pequenos sons para a base de dados do Telepoesis.Net, escolhendo-os, posteriormente, conforme passo anterior.

Pode ainda escolher, para efeitos de publicação e organização no blog Poemário, as seguintes opções:

A Dir WP: Permite escolher ou criar um directório próprio no blog Poemário. Possibilidades de categorias no blog existentes incluem "Poemas no Meio do Caminho", "Húmus Poema Contínuo", "Amor de Clarice", etc.

\section{Poemário - Poema - programa XML}

Finalmente, o autor, depois de programado o poema (passo 1), depois de criadas e guardadas as categorias e listas (passo 2) e depois de configurar algumas opções (passo 3), pode agora gerar o XML (poema-programa) que permitirá ao motor textual Poemário criar e interpretar em tempo real o poema. Para isso, basta clicar no botão "Gera XML" disponível na área 4 do Poemário, após o que será gerado o XML do poema na área à esquerda do ponto 4 .

\section{Poemário - Ler Poema e enviar para blog}

O autor pode agora clicar no botão "Mostra poema" para criar o poema combinatório que programou.

Se quiser partilhar as suas experiências com outros utilizadores do Poemário, pode utilizar a opção/botão "Publica poema".

Pode ainda enviar, sempre que o desejar, as leituras de poemas para o Blog Poemário (http://telepoesis.net/poemario) bastando para isso utilizar o botão "@” - enviar para blog disponível nos poemas gerados. 
Se 0 autor desejar actuar fora das bases de dados do Poemário (blog e galeria), pode gravar o XML num ficheiro de texto com extensão *.xml. Para isso, bastará seleccionar o XML gerado, copiar para o clipboard do computador e colá-lo num editor de texto simples (Notepad ou WordPad). Sempre que quiser ler o poema, pode regressar ao Poemário inserindo o código final na secção 4.

Apresentaremos a seguir um conjunto de poemas criados com este software e posteriormente integrados em ambientes hipermediáticos distintos.

\section{PoemAds. Sob o signo da devoração - Releitura, escrileitura, desocultação}

PoemAds ${ }^{2}$ é um trabalho na área da combinatória textual que, como o subtítulo indica, parte de um conjunto de textos que promovem a devoração de slogans publicitários.

Em primeiro lugar, foram seleccionados um conjunto de slogans de publicidade, nomeadamente: Com Flora, tudo melhora - Flora; Sabor Autêntico - Super Bock; Não é Água. É Castello - Água Castello; O poder da natureza é infinito Pedras Salgadas; A pausa que refresca - Coca-cola; Compal é mesmo natural Compal; Puro Prazer - logurte Adagio; Brincadeiras de bom gosto - Óleo Fula; O Bom, Sai Bem - Pescada Pescanova; Pelo prazer de conduzir - BMW; Movidos pela paixão - Fiat; $A$ vida inspira-nos - Millennium BCP; Valores que crescem consigo - Montepio; Há coisas que o dinheiro não compra. Para todas as outras existe MasterCard - MasterCard; Ter é poder - Unibanco; Chega de lágrimas - Champô Johnson \& Johnson; Campeão de preços - Continente; Sabe bem pagar tão pouco - Pingo Doce; A vida em Movimento - Metro do Porto; A criar excêntricos todas as semanas - Euromilhões; Aposte nos seus sonhos - Lotaria Clássica; Porque a vida é agora - Visa.

2 TORRES, R. (2012). PoemAds - Sob o signo da devoração. Utilização paródica de slogans publicitários para construção generativa de poesia. <http://www.telepoesis.net/poemads>. Créditos: Rui Torres: concepção, desenho e programação textual, textos (a partir de Slogans publicitários); Nuno F. Ferreira: programação (Poemário). 
Após esta selecção, criou-se o poema central deste texto, subvertendo o contexto dos slogans seleccionados: "Não é consumo. É dependência - / rancor autêntico / a pausa que anula. / O poder da plagiotropia é profundo - / puro esquecimento. / Há coisas que o crédito não alcança - / para todas as outras existe devoração. / Movidos pela antropofagia / - pelo prazer de parodiar - / a publicidade inspira-nos. / Imagens que crescem consigo / - a vida em movimento - / a criar excêntricos todas as semanas. / Aposte nos seus sonhos! / Com crédito, tudo melhora - / o bom sai bem, / ter é poder. / Chega de lamúrias! / Sabe bem pagar tão pouco e / inspiração é mesmo natural: / espuma de preços / porque a vida é agora!"

Este poema-base foi programado no Poemário e o seu resultado inserido numa página HTML com quatro (4) banners, os quais seguem os Core Standard Ad Units propostos pelo IAB: o Banner Leaderboard $(728 \times 90 \mathrm{px})$ no topo e fundo da página, e o Banner Wide Skyscraper (160 x 600 px) na esquerda e direita. Nestes banners, slogans são gerados a partir dos elementos em cima referidos, acrescidos de uma depuração iconográfica que parodia, de um modo plagiotrópico, o design visual da publicidade actual.

Para a criação do léxico a animar estes poemas, fez-se uma recolha, estudo e classificação de dezenas de milhares de slogans, comerciais e institucionais. PoemAds, através de procedimentos combinatórios e generativos próprios da literatura electrónica, promove a deformação e transformação da publicidade, despertando o leitor para uma releitura crítica e reflexiva dos slogans que cerceiam e limitam a sua liberdade criativa. 


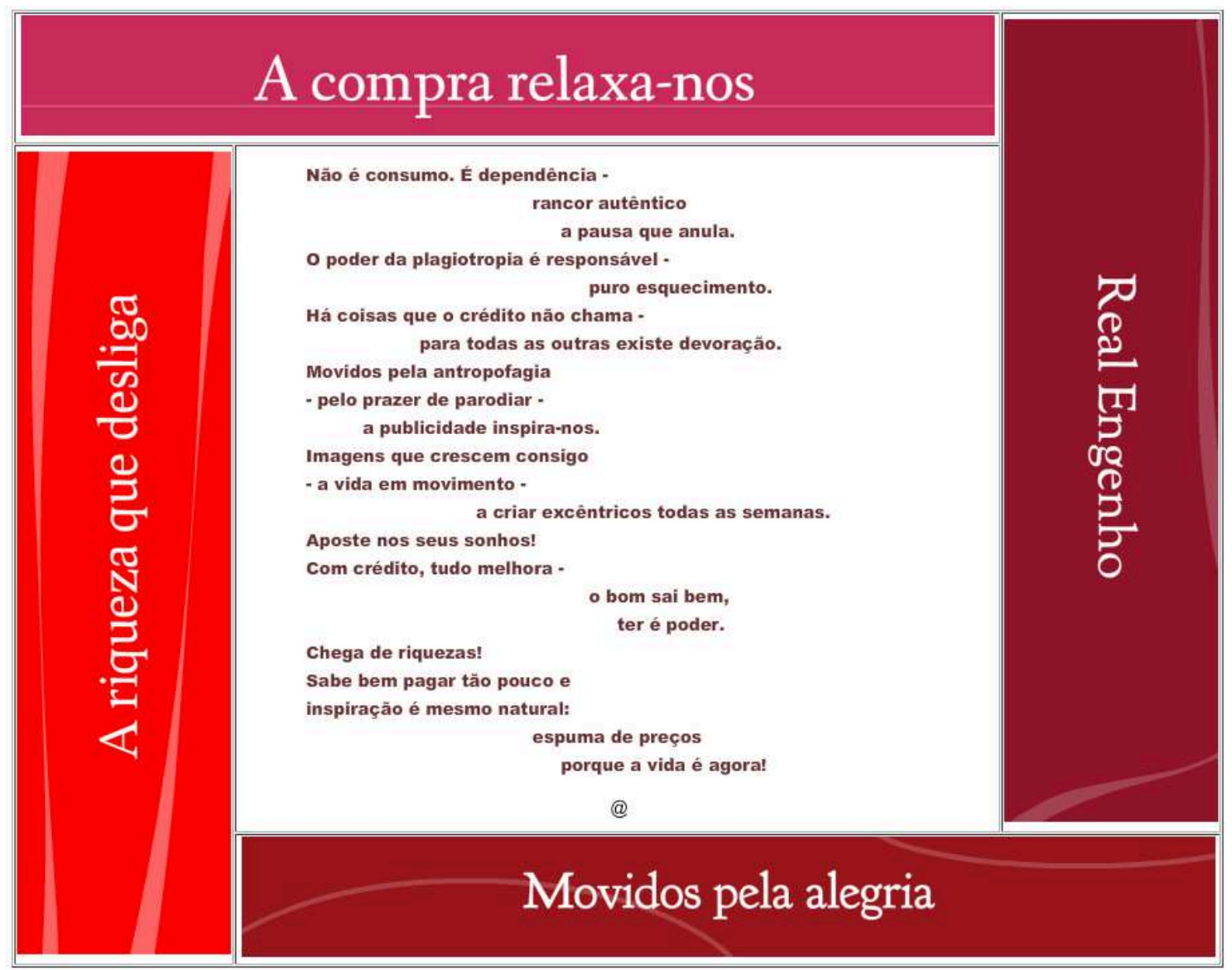

Fig. 2 - Imagem de PoemAds

\section{SUSTAINABILITY AND ENTROPY IN TEXTUAL VARIATIONAL GENERATION: POEMADS - UNDER THE SIGN OF DEVOURINGNESS}

ABSTRACT: Description and theoretical context of PoemaAds, a set of digital poems performed with the support of the literary software "Poemario", following generative and combinatorial procedures. This work of electronic literature was programmed from the combination of various advertising slogans, thus constituting a plagiotropia and creative transformation of contemporary advertising. The lexicon that feeds these processes was treated and selected from $+10,000$ advertisements and propaganda in Portuguese language.

KEYWORDS: Cyberliterature. Textual combinatory and generativity. Plagiotropia and rereading. Information Theory.

\section{Referências}

BANKSY. Cut it Out. London: Weapons of Mass Distraction, 2004.

BARBOSA, Pedro. Aspectos quânticos do Cibertexto. In: Cibertextualidades. v. 1. Porto, 2006. p. 11-42. 
BENSE, Max. Pequena Estética. Trad. Haroldo de Campos. 2a. ed. São Paulo: Perspectiva, 1975.

DEBORD, Guy; WOLMAN, Gil J. A User's Guide to Détournement. In: Situationist International Anthology. Ed. e trad. Ken Knabb. Bureau of Public Secrets, 2006. Disponível em: http://www.bopsecrets.org/SI/detourn.htm.

GOMES, Maria dos Prazeres. Outrora agora: relações dialógicas na poesia portuguesa de invenção. São Paulo: EDUC, 1993.

HERBERTO, Helder. Electronicolírica. Lisboa: Guimarães Editores, 1964.

HUTCHEON, Linda. Uma Teoria da Paródia. Trad. Teresa Louro Pérez. Lisboa: Edições 70, 1989.

MELO E CASTRO, E. M. de. A proposição 2.01. Poesia Experimental. Lisboa: Ulisseia, 1965.

MOLES, Abraham A. Information Theory and Esthetic Perception. Trad. Joel F. Cohen. Urbana: U of Illinois P, 1966.

NAMORA, Fernando. Marketing (1959-1969). Lisboa: Publicações EuropaAmérica, 1970.

SHKLOVSKY, Viktor. Art as Technique. In: DAVIS, Robert Con; SCHLEIFER, Ronald (ed.). Contemporary Literary Criticism. . 2a. ed. New York: Longman, 1989. p. 54-66.

Texto recebido em 31/10/2012. 